\title{
NUMERICAL INVESTIGATION OF THE INTERACTION BETWEEN LINEAR/NONLINEAR WAVES AND BREAKWATER
}

\author{
LUZHONG SHAO \& JIE LUO \\ PLA University of Science and Technology, Nanjing, China
}

\begin{abstract}
Based on the Reynolds-Averaged Navier-Stokes (RANS) equations and the Volume of Fluid (VOF) method, a numerical wave tank, including wave generation, propagation and damping zones, is set up. Nonlinear regular waves of large amplitude are simulated in a vertical two-dimensional (2D) wave flume. The wave generation with the relaxation zone, which damps the reflected waves from structures in the numerical wave flume, is implemented using the momentum source method. The computed wave profiles agree well with the target wave profiles. Interactions between wave and floating semisubmersible box-type breakwater are studied. The relationships between the ratio of breakwater length to wavelength and transmission coefficients are predicted and compared with the analytical solution of linear waves and the experimental data. Results demonstrate that the transmission coefficient is markedly affected by both ratio of breakwater length to wavelength and the water draught. But wave amplitude does not distinctly affect the transmission coefficient for regular waves. For the cases of interaction of a floating breakwater and large amplitude wave, the effects of wave breaking, run-up and overtopping are discussed.

Keywords: floating breakwater, momentum source term, numerical wave tank, transmission coefficient.
\end{abstract}

\section{INTRODUCTION}

Floating breakwaters are commonly used to protect shorelines and offshore engineering structures, such as moored vessels, harbours and marine structures, from wave attacks. Compared with bottom-fixed breakwaters, floating breakwaters have some advantages in terms of environmental friendliness, low cost, flexibility and mobility. They are especially economical for coastal zones with a high tidal range or deep water depth. Moreover, they may even be the only viable option for locations with soft bottom foundation and for deep water zones.

The general desirable characteristics of a floating breakwater include high costeffectiveness, good wave reduction and low force requirements on the mooring system and connecting components. Previously, Hales [1] and McCartney [2] comprehensively reviewed various floating breakwater concepts to evaluate their performance and applicability. Since then, floating breakwaters with other novel configurations have also been proposed for better performance by Murali and Mani [3], Liang et al. [4], Gesraha [5], Dong et al. [6], Wang and Sun [7] and Uzaki et al. [8]. Hales [1] pointed out that a floating breakwater should be as simple, durable and maintenance-free as possible for long-time operation in real seas, and that highly complex structures should be avoided. Floating breakwaters with a rectangular cross-section may thus be most suitable to satisfy these requirements. 
For various $2 \mathrm{D}$ free or moored floating breakwaters with a rectangular cross-section, extensive theoretical, experimental and numerical research was reported in the literature. Isaacson [9] applied a numerical model, based on potential theory coupled with the equations of motion for the rigid body, to obtain the flow characteristics and dynamic response of a floating body. Fugazza and Natale [10] presented a coupled solution for diffraction and body movement in order to eliminate the errors that occur from linear superposition of the separate simulations. They also presented results from the above numerical model and experimental data, concerning the energy losses and floating breakwater response.

Experimental studies have been conducted to study the wave-floating structure interaction. Murali and Mani [3] examined the feasibility of a cage-type floating breakwater and presented the dependence of the transmission coefficient $(\mathrm{Ct})$ that depends on the ratio of structure length to wavelength, the structure draught to water depth and the wave steepness parameter. Moreover, they found that by fixing a row of pipes below the floating body, they achieved the same $\mathrm{Ct}$ with smaller ratio of structure length to wavelength. Koutandos et al. [11] presented an experimental study of waves acting on floating breakwater with four different configurations (single fixed, heave motion free, single fixed with attached front plate and double fixed) in shallow and intermediate waters. It was noted that the effect of the various configurations on the transmission, reflection and energy dissipation coefficients is significant. Experiments with regular, deep-water waves acting on either a fixed floating rectangular structure or a free-rolling structure were presented by Jung et al. [12, 13]. Detailed velocity measurements were performed by using the Particle Image Velocimetry (PIV), and 2D flow characteristics such as mean velocity field, vortex generation and evolution and turbulence properties were presented.

The purpose of this study is to investigate the interaction of the waves of various amplitude, especially the large-amplitude wave, with the floating breakwater. The numerical wave tank was set up and the momentum source term method was applied to generate regular waves at the wave making zone and to damp the reflected wave at the wave relaxing zone to avoid the secondly reflected wave from the wave-maker. The floating breakwater is fixed near the free surface with different draught. Transmission coefficients were obtained numerically and experimentally in terms of wave amplitude, the wave period and the submerged depth or water draught.

\section{NUMERICAL METHOD}

\subsection{Governing equations}

The RANS equations were employed to establish a numerical model of interaction of water waves and with a fixed floating breakwater. The flow of fluids, including air and water, could be described by the equation of mass conservation, or continuity equation as

$$
\frac{\partial \rho}{\partial t}+\frac{\partial}{\partial x_{i}}\left(\rho u_{i}\right)=0
$$

and the momentum conservation equation as

$$
\frac{\partial}{\partial t}\left(\rho u_{i}\right)+\frac{\partial}{\partial x_{j}}\left(\rho u_{i} u_{j}\right)=-\frac{\partial p}{\partial x_{i}}+\frac{\partial \tau_{i j}}{\partial x_{j}}+\rho g_{i}+F_{i},
$$


where $\rho$ is the fluid density, including air and water; $u_{i}$, with i being 1,2 or 3 , is the velocity of fluid particle; $x_{i}$ is the axis of coordinates; $g_{i}$ is the gravitational acceleration and $F_{i}$ is the external force acting on the fluid; $\tau_{i j}$ is the Reynolds stress tensor.

\subsection{Numerical wave generation approach}

According to the source wave theory, the source term could be added to the continuity equation or the momentum equation for the sake of making wave and damping wave. In this paper, only the momentum equation included the source term. After making wave and damping wave, the fluid field could be described as

$$
\left\{\begin{array}{l}
u_{i M}=C u_{i C}+(1-C) u_{i I} \\
P_{M}=C P_{C}+(1-C) P_{I}
\end{array},\right.
$$

where the subscript $\mathrm{C}$ denotes the computed values at present time step; I denotes variables for the incidence wave; $C=C(x)$ is the smoothing function. At the wave-maker zone, it can be written as

$$
C(x)=\sin \left(\frac{\pi}{2} x\right)^{2} \tanh (5 x) .
$$

At the damping zone, it can be defined as

$$
C(x)=\left(0.9995+0.0005 x-e^{-\frac{x}{0.05}}\right)^{100} .
$$

The momentum equation with an additional source term and the additional source term momentum equation at the $i=1$ direction can be discretized as follows, respectively

$$
\begin{gathered}
\rho \frac{u_{1 C}^{N+1}-u_{1 C}^{N}}{\Delta t}+\rho u_{i C} \cdot \frac{\partial u_{1 C}}{\partial x_{i}}=-\frac{\partial P_{C}}{\partial x_{1}}+F_{1}, \\
\rho \frac{u_{1 M}^{N+1}-u_{1 M}^{N}}{\Delta t}+\rho u_{i M} \cdot \frac{\partial u_{1 M}}{\partial x_{i}}=-\frac{\partial P_{M}}{\partial x_{1}} .
\end{gathered}
$$

Substituting variables with subscript $M$ of eqn (3) into eqn (7), we can obtain the source term in eqn (6)

$$
\begin{gathered}
F_{1}=\frac{\rho}{\Delta t}(C-1)\left(u_{1 C}^{N}-u_{1 I}^{N}\right)+F_{1 C O N}+F_{1 P R E}, \\
F_{1 C O N}=-\rho\left\{\left(C^{2}-1\right)\left(u_{1 C} \frac{\partial}{\partial x_{1}}+u_{2 C} \frac{\partial}{\partial x_{2}}\right) u_{1 C}+\left(1-C^{2}\right)\left(u_{1 I} \frac{\partial}{\partial x_{1}}+u_{2 I} \frac{\partial}{\partial x_{2}}\right) u_{1 I}\right. \\
\left.+C(1-C)\left[\left(u_{1 C} \frac{\partial}{\partial x_{1}}+u_{2 C} \frac{\partial}{\partial x_{2}}\right) u_{1 I}+\left(u_{1 I} \frac{\partial}{\partial x_{1}}+u_{2 I} \frac{\partial}{\partial x_{2}}\right) u_{1 C}\right]\right\},
\end{gathered}
$$




$$
F_{1 P R E}=\rho(1-C)\left(\frac{1}{\rho} \frac{\partial P_{c}}{\partial x_{1}}+\frac{\partial u_{1 I}}{\partial t}+u_{i I} \cdot \frac{\partial u_{1 I}}{\partial x_{i}}\right)
$$

Similarly, the source terms at the $i=2$ and $i=3$ directions can be obtained solving the corresponding discretized equations. Then the flow field including velocity and pressure in combination with the source terms and the weighting function at the wave-making zone can be written as

$$
u_{i M}=C u_{i I} ; P_{M}=C P_{I} .
$$

At the wave-relaxing zone, the relaxation solution is

$$
u_{i M}=C u_{i C}+(1-C) u_{i l} ; P_{M}=C P_{C}+(1-C) P_{I} .
$$

At the wave-sponging zone or damping zone, it is

$$
u_{i M}=C u_{i C} ; P_{M}=C P_{C} \text {. }
$$

If only add the source terms into the original equations, the drift velocity will appear. According to the Stokes wave theory, the drift velocity can be evaluated simply by

$$
q_{d r i f t}=\frac{\pi H^{2}}{4 T} \frac{1}{\tanh (k D)}
$$

For strong nonlinear waves, the stream function wave theory is applied to generate regular waves of large amplitude. The numerical wave tank is presented in Fig. 1. It is divided into four parts: wave-making zone, wave-relaxing zone, wave-working zone and wave-sponging zone successively from left to right. The purpose for establishing a wave-relaxing zone is to absorb the reflected wave from the floating breakwater boundary. First, the numerical wave tank is verified and then the floating box-type breakwater with various water draught is put into the wave-working zone to compute the interaction of the wave of various amplitudes with the breakwater.

\subsection{Numerical aspects}

The dimension of the numerical wave tank is $50 \mathrm{~m} \times 0.8 \mathrm{~m} \times 1.2 \mathrm{~m}$, and, because the wave only propagates along the $\mathrm{x}$ direction and the floating box-type can be regarded as infinite at the longitude direction, the problem can be formulated as a 2D case. However, the computational

\begin{tabular}{|l|l|c|l|}
\hline & & \multicolumn{1}{|c|}{$\nabla$} & \\
\hline $\begin{array}{l}\text { wave } \\
\text { making } \\
\text { zone }\end{array}$ & $\begin{array}{l}\text { wave } \\
\text { relaxing } \\
\text { zone }\end{array}$ & wave working zone & $\begin{array}{l}\text { wave } \\
\text { sponging } \\
\text { zone }\end{array}$ \\
\hline
\end{tabular}

Figure 1: Sketch of the numerical wave tank and the floating breakwater. 


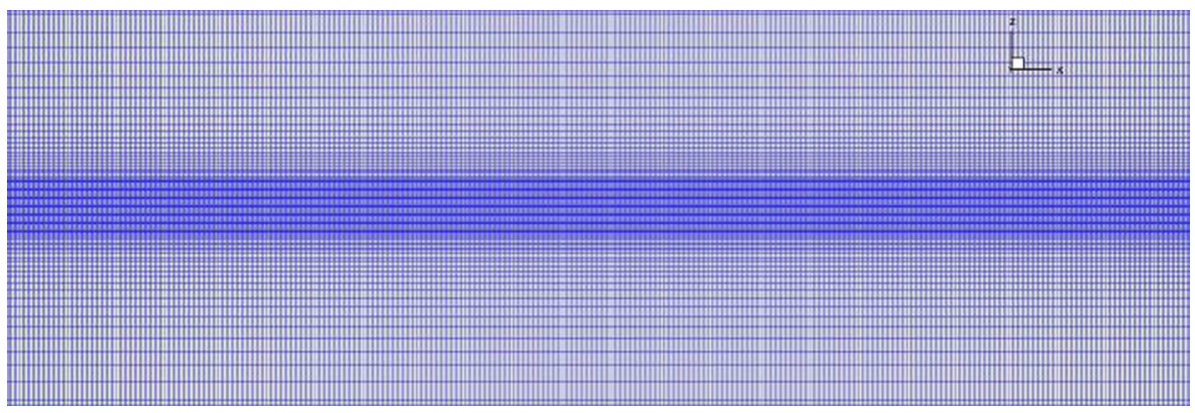

Figure 2: Computational grids near the free surface.

grid is reduced to a pseudo three-dimensional one; this means only one grid is required at the longitude direction in the numerical simulations. At the space between the wave trough and wave crest along the $\mathrm{z}$ direction, the grid size is uniform and $\Delta x=0.004$. The grid at $\mathrm{x}$ direction is uniform, i.e. $\Delta x=0.012$, and there is only one grid at y direction. The maximum and minimum wavelengths are $4.628 \mathrm{~m}$ and $1.258 \mathrm{~m}$, respectively. There are at least 104 grids within one wavelength at the $\mathrm{x}$ direction. The computational mesh is shown in Fig. 2. The non slip boundary conditions are used at the left boundary, the right boundary and the bottom boundary. The top boundary is formulated as a pressure inlet boundary. The lateral boundaries at y direction are considered symmetry boundaries. The lengths of the wavemaking zone, wave-relaxing zone and the wave-sponging zone are $10 \mathrm{~m}$, and the wave-making zone is $20 \mathrm{~m}$.

The mesh is generated by OpenFOAM, which is a free and open package. The VOF method and the RNG $k-\varepsilon$ turbulence model are selected in the following computations. PISO scheme for pressure-velocity coupling computation and the body force weighted scheme are employed to solve the governing equations. The geo-reconstruction scheme is enabled to capture the free surface. The solutions are considered to be converged when the residuals are less than $10^{-3}$. The time step size is $10^{-3}$ and it is good enough for modelling regular waves of both small and large amplitude to get solutions converged. The maximum physical time is $30 \mathrm{~s}$ for each numerical simulation case.

The computations are performed at a computer cluster, which has 20 nodes, and each node has 12 processors with $3.4 \mathrm{GHz}$ and $32 \mathrm{~GB}$ RAM. Only one node is employed to compute one case and the real run time is less than 30 hours.

\section{NUMERICAL RESULTS AND DISCUSSIONS}

\subsection{The linear analytic solution}

Based on the linear wave theory, an analytic solution of wave-floating breakwater was proposed by Drimer et al. [14] in the finite water depth. The transmission coefficient for fixed box-type breakwater can be presented as

$$
T=\frac{\mathrm{i} U_{0}^{2} / k}{S B+\mathrm{i} U_{0}^{2} / k+\sum_{n=1}^{\infty} \frac{U_{n}^{2}}{k_{n}},}
$$


where B is the half width of the breakwater; $\mathrm{S}=\mathrm{h}-\mathrm{d} ; \mathrm{h}$ is the water depth and $\mathrm{d}$ is the draught; $\mathrm{k}$ is the wave number of incident wave; and $U_{n}$ can be expressed as

$$
U_{n}=\int_{-h}^{-d} f_{n} \mathrm{~d} z \quad(n=0,1,2, \ldots),
$$

where

$$
\begin{gathered}
f_{0}=\frac{\sqrt{2} \cosh [k(z+h)]}{\left[h+\sigma^{-1} \sinh ^{2}(k h)\right]^{1 / 2}}, \\
f_{n}=\frac{\sqrt{2} \cos \left[k_{n}(z+h)\right]}{\left[h-\sigma^{-1} \sin ^{2}\left(k_{n} h\right)\right]^{1 / 2}} \quad(n=1,2, \ldots) .
\end{gathered}
$$

In the above equations, $\mathrm{k}$ satisfies the dispersion relation

$$
\sigma=\frac{\omega^{2}}{\mathrm{~g}}=k \tanh (k h),
$$

where $\omega$ is the wave angular frequency; $\mathrm{g}$ is the gravity acceleration; $k_{n}$ are the positive roots of the following equation

$$
\sigma=-k_{n} \tanh \left(k_{n} h\right)
$$

The transmission coefficient of breakwater can be obtained to calculate the module of the complex number $\mathrm{T}$ in eqn (15).

\subsection{Verification of numerical wave tank}

Supposing the wave number is $4.993 \mathrm{~m}^{-1}$ and the wave height is $0.06 \mathrm{~m}$, the wave period is obtained by employing the parameters of wave number and wave amplitude according to the stream function wave theory. A comparison of the computed time series of the surface elevation with the stream function wave theory is presented in Fig. 3a. For the regular wave of large amplitude, the numerical result of the time series of surface elevation for the case of $\mathrm{T}=1.0537 \mathrm{~s}$ and $\mathrm{H}=0.21 \mathrm{~m}$ is also compared with the stream function wave theory, as shown in Fig. 3b. A good agreement can be found between the computed wave profile and the stream function wave theory, which represents that the numerical wave flume with the wave generation approach works well for modelling regular waves of large amplitude.

In the following computations on effects of breakwater on waves, the lengths of the working zone, relaxing zone and sponging zone were all set to $10 \mathrm{~m}$, and this is convenient for cases with different wave parameters. The centre of the floating breakwater is located at the wave-working zone and was $30.175 \mathrm{~m}$ away from the left boundary of the numerical wave tank. The length of the numerical wave tank was $50 \mathrm{~m}$, which is equal to the physical flume length.

The small amplitude wave is defined as the ratio of wave height to water depth $H / h \leq 0.2$ and large amplitude $H / h \leq 0.2$. First, we investigated the transmission coefficient variations versus the ratio of the length of breakwater over the wavelength for small and large amplitude. Then some typical wave profiles were plotted. 


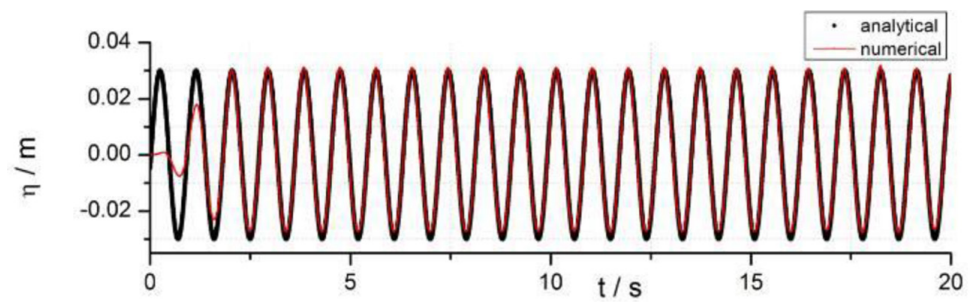

(a) small amplitude

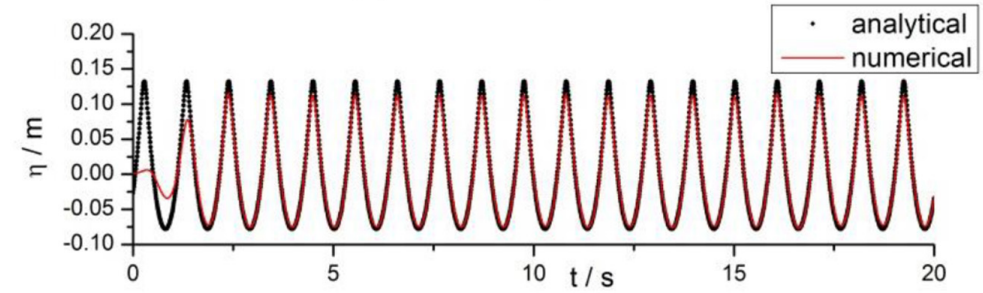

(b) large amplitude

Figure 3: Comparison of the surface elevation between the stream function wave theory and the numerical results.

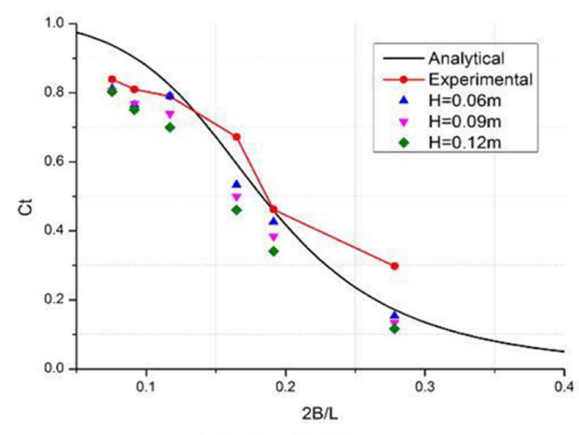

(a) $\mathrm{dr}=0.09 \mathrm{~m}$

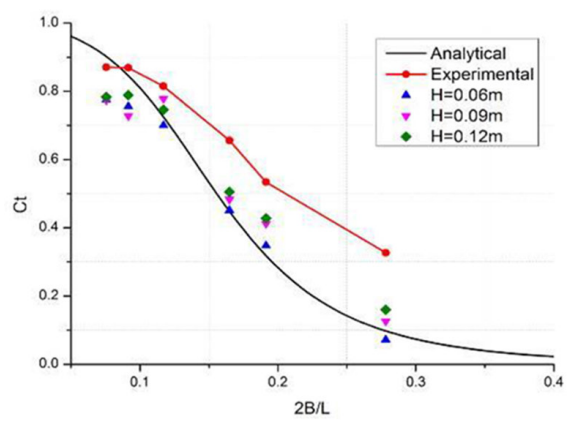

(c) $\mathrm{dr}=0.15 \mathrm{~m}$

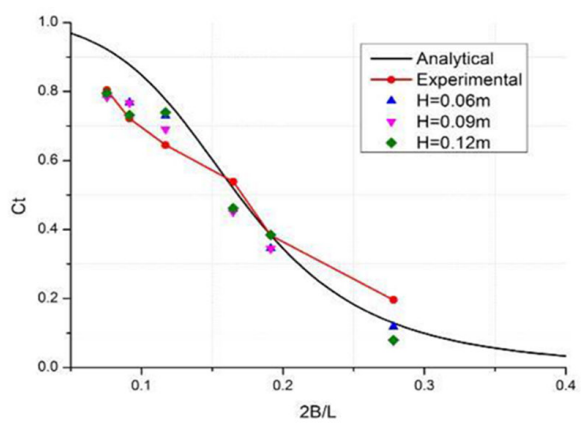

(b) $\mathrm{dr}=0.12 \mathrm{~m}$

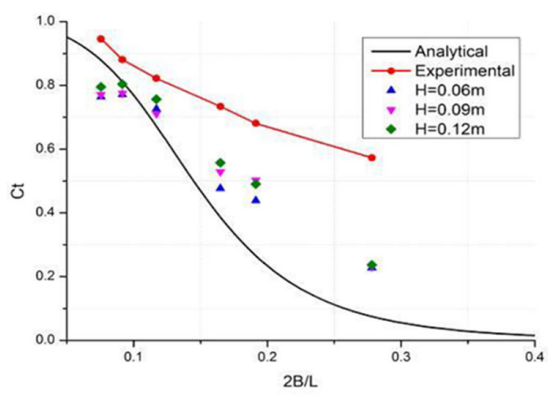

(d) $\mathrm{dr}=0.18 \mathrm{~m}$

Figure 4: Transmission coefficient versus the ratio of the breakwater length to the wavelength with small wave amplitude. 


\subsection{Transmission coefficient}

A corresponding experiment was carried out in a wave flume at Shanghai Jiao Tong University. The wave flume was $50 \mathrm{~m}$ in length, $0.8 \mathrm{~m}$ in width and $1.2 \mathrm{~m}$ in depth. A piston-type wave-maker with a hydraulic servo system was used to generate waves. Wave gauges were installed to measure wave heights of the incident wave and the transmission wave. The ratio of transmission wave height to incident wave height is defined as the transmission coefficient. The dimension of the floating breakwater is $0.35 \mathrm{~m} \times$ $0.8 \mathrm{~m} \times 0.15 \mathrm{~m}$. Transmission coefficients measured from the physical model experiment are compared with the computed transmission coefficients from the numerical computations.

For cases of small amplitude waves, saying $H / h \leq 0.2$, Figs $4 a-d$ depict the transmission coefficient versus the ratio of the breakwater length to the wavelength with water draught $0.09 \mathrm{~m}, 0.12 \mathrm{~m}, 0.15 \mathrm{~m}$ and $0.18 \mathrm{~m}$, respectively. The solid line represents the analytical result calculated by eqn (15), which is independent with the amplitude of incoming wave. The solid line with dots is the experimental data with wave amplitude $H=0.06 \mathrm{~m}$. The symbols are the computed values from numerical simulations, in which three cases of different wave amplitude are considered.

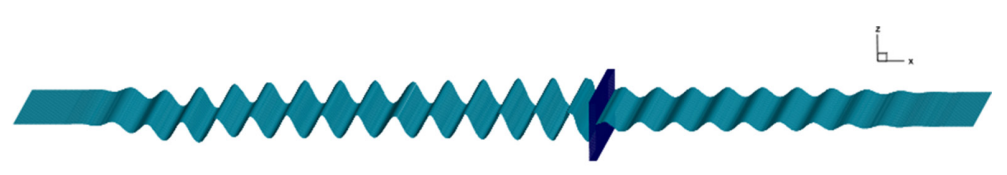

(a) $\mathrm{T}=1.1 \mathrm{~s}, \mathrm{H}=0.06 \mathrm{~m}, \mathrm{dr}=0.09 \mathrm{~m}$

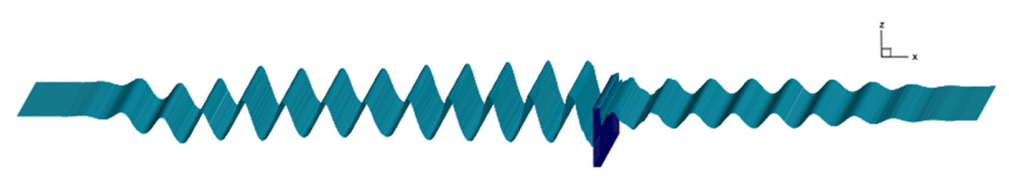

(b) $\mathrm{T}=1.2 \mathrm{~s}, \mathrm{H}=0.09 \mathrm{~m}, \mathrm{dr}=0.12 \mathrm{~m}$

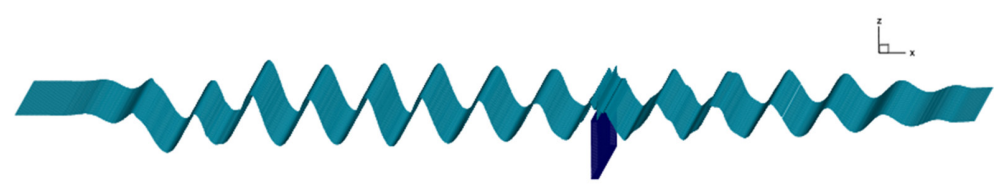

(c) $\mathrm{T}=1.5 \mathrm{~s}, \mathrm{H}=0.12 \mathrm{~m}, \mathrm{dr}=0.15 \mathrm{~m}$

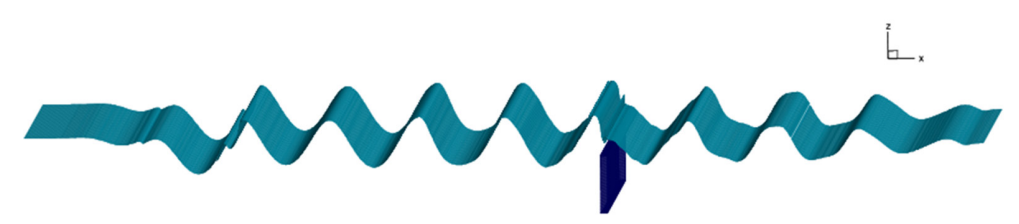

(d) $\mathrm{T}=2.1 \mathrm{~s}, \mathrm{H}=0.12 \mathrm{~m}, \mathrm{dr}=0.18 \mathrm{~m}$

Figure 5: Wave profiles with small amplitude. 
The snapshots of wave field affected by the breakwater are shown in Fig. 5. The ratio of $x$ to $\mathrm{z}$ was set to be $1 / 20$ in the figure. Figures $5 \mathrm{a}-\mathrm{d}$ are the wave profiles with $\mathrm{T}=1.1 \mathrm{~s}, \mathrm{H}=$ $0.06 \mathrm{~m}, \mathrm{dr}=0.09 \mathrm{~m} ; \mathrm{T}=1.2 \mathrm{~s}, \mathrm{H}=0.09 \mathrm{~m}, \mathrm{dr}=0.12 \mathrm{~m} ; \mathrm{T}=1.5 \mathrm{~s}, \mathrm{H}=0.12 \mathrm{~m}, \mathrm{dr}=0.15 \mathrm{~m}$; and $\mathrm{T}=2.1 \mathrm{~s}, \mathrm{H}=0.12 \mathrm{~m}, \mathrm{dr}=0.18 \mathrm{~m}$, respectively.

The differences of the analysis, numeric simulation and physical experiment are slight for small water draught cases, saying $\mathrm{dr}=0.09 \mathrm{~m}$ and $\mathrm{dr}=0.12 \mathrm{~m}$, as shown in Figs $4 \mathrm{a}$ and $\mathrm{b}$. But for large water draught, saying $\mathrm{dr}=0.15 \mathrm{~m}$ and $\mathrm{dr}=0.18 \mathrm{~m}$, analytical results are mostly smaller than the numerical and experimental ones, as shown in Figs $4 \mathrm{c}$ and d, because the breakwater is totally submerged into water, as seen in Figs $5 \mathrm{c}$ and d, which are different from Figs $5 \mathrm{a}$ and $\mathrm{b}$, but the analysis does not take this factor into consideration. For all cases in Fig. 4, the experimental results are larger than numerical ones because the wave flume cannot eliminate the reflected wave from the breakwater and the reflect wave will interact with the incoming wave.

For cases of large amplitude waves, say $H / h>0.02$, the transmission coefficient versus the ratio of the breakwater length to the wavelength is shown in Figs $6 \mathrm{a}-\mathrm{d}$ with water draught $0.09 \mathrm{~m}, 0.12 \mathrm{~m}, 0.15 \mathrm{~m}$ and $0.18 \mathrm{~m}$, respectively. The solid line with dots indicates experimental data with wave amplitude $H=0.06 \mathrm{~m}$. The symbols denote the numerical results for different wave amplitude $H=0.15 \mathrm{~m}, H=0.18 \mathrm{~m}$ and $H=0.21 \mathrm{~m}$.

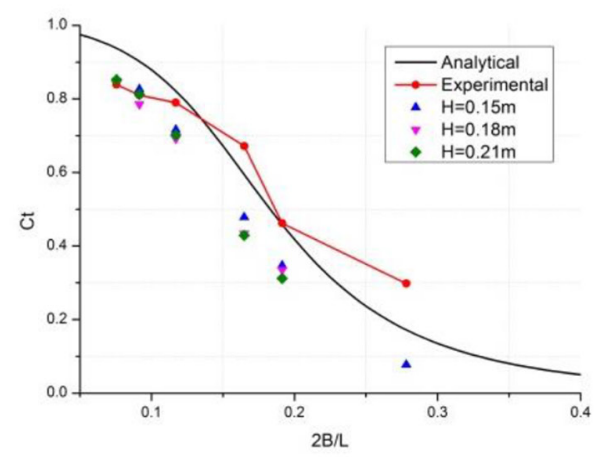

Transmission coefficient $(\mathrm{dr}=0.09 \mathrm{~m})$

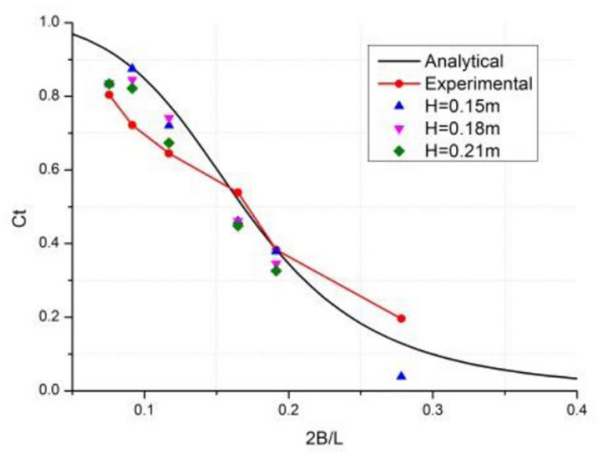

Transmission coefficient $(\mathrm{dr}=0.12 \mathrm{~m})$

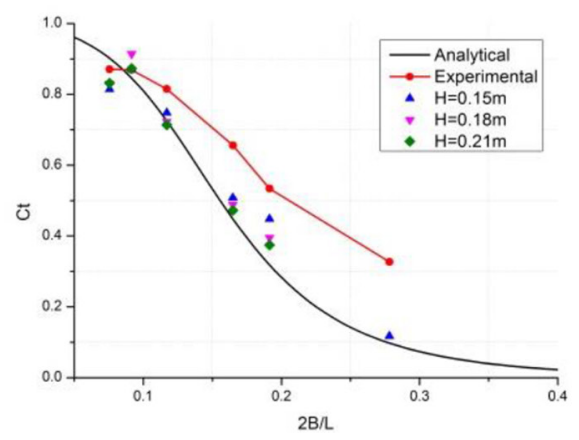

Transmission coefficient $(\mathrm{dr}=0.15 \mathrm{~m})$

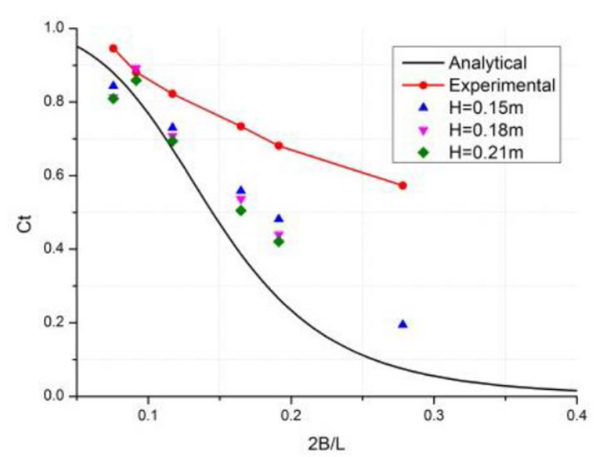

Transmission coefficient $(\mathrm{dr}=0.18 \mathrm{~m})$

Figure 6: Transmission coefficient versus the ratio of the breakwater length to the wavelength with large amplitude. 

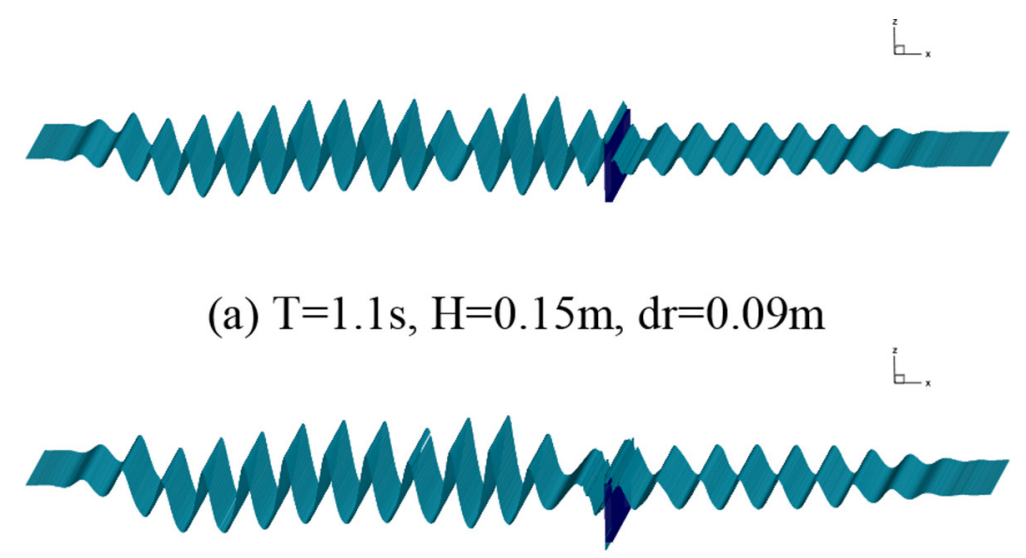

(b) $\mathrm{T}=1.2 \mathrm{~s}, \mathrm{H}=0.18 \mathrm{~m}, \mathrm{dr}=0.12 \mathrm{~m}$

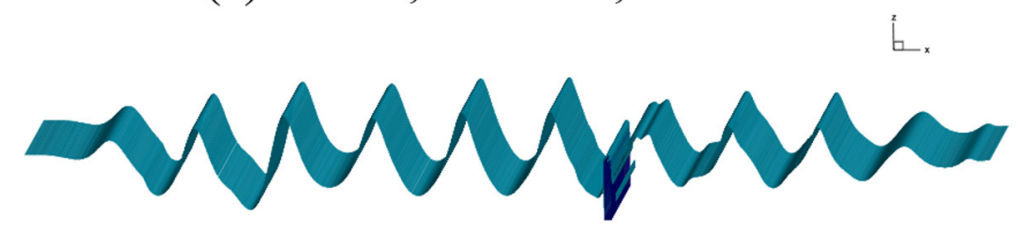

(c) $\mathrm{T}=1.5 \mathrm{~s}, \mathrm{H}=0.21 \mathrm{~m}, \mathrm{dr}=0.15 \mathrm{~m}$

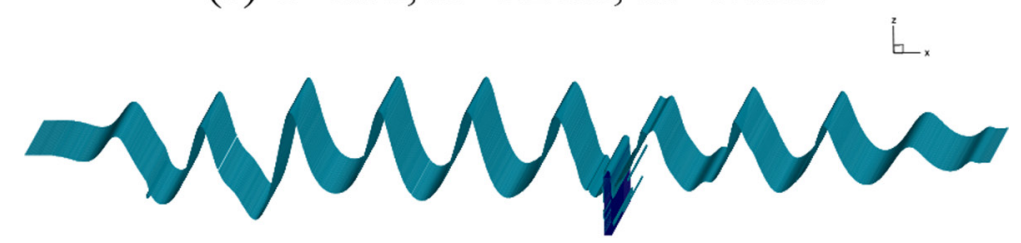

(d) $\mathrm{T}=2.1 \mathrm{~s}, \mathrm{H}=0.21 \mathrm{~m}, \mathrm{dr}=0.18 \mathrm{~m}$

Figure 7: Wave profiles with large amplitude.

Figure 7 depicts the snapshots of wave profile in the numerical wave flume with the breakwater. Four cases of different parameters in computations are as follows: $\mathrm{T}=1.1 \mathrm{~s}$, $\mathrm{H}=0.15 \mathrm{~m}, \mathrm{dr}=0.09 \mathrm{~m} ; \mathrm{T}=1.2 \mathrm{~s}, \mathrm{H}=0.18 \mathrm{~m}, \mathrm{dr}=0.12 \mathrm{~m} ; \mathrm{T}=1.5 \mathrm{~s}, \mathrm{H}=0.21 \mathrm{~m}, \mathrm{dr}=0.15$ $\mathrm{m} ; \mathrm{T}=2.1 \mathrm{~s}, \mathrm{H}=0.21 \mathrm{~m}, \mathrm{dr}=0.18 \mathrm{~m}$.

The results in Fig. 6 are slightly different from Fig. 4, and the reason for this is almost the same as discussed above for Fig. 4. But for large amplitude waves, the wave run-up and overtopping the top of the breakwater always exist even for small water draught, such as $\mathrm{dr}=0.09 \mathrm{~m}$. This phenomenon does not affect the transmission coefficient distinctively, but it may slam the breakwater and produce violent forces. For some cases, wave run-up along the propagation direction at the fore of the breakwater and overtopping occur, as shown in Fig. 8 . 


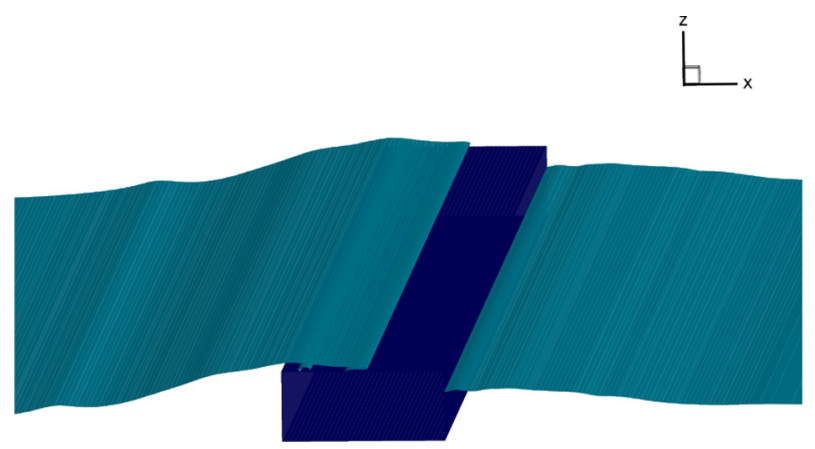

Figure 8: Wave run-up and overtopping.

\section{CONCLUSIONS}

Based on the RANS equations and the VOF method, a numerical wave tank was implemented to study interaction of regular waves and breakwaters. Physical experiments were also carried out in a wave flume to measure the transmission coefficient of various wave parameters and breakwater draught. The numerical results were compared with the linear analytic solution and experimental data.

It was found that the ratio of breakwater length to wavelength is a principal parameter to affect the transmission coefficient. The smaller the ratio, the larger the coefficient for different wave amplitude. This implies that the long wave has strong penetration capacity. The water draught can influence the transmission coefficient markedly for the four water draught cases. Transmission coefficient is proportional to the water draught. In essence, wave amplitude slightly affects the transmission coefficient. However, much complex hydrodynamic phenomena appear due to violent deformation of waves and overtopping over the breakwaters for incoming waves of large amplitude.

\section{REFERENCES}

[1] Hales, L.Z., Floating breakwaters: state-of-the-art literature review. US Army Engineer Waterways Experiment Station. Vicksburg, Mississippi, USA. Technical Report No. 81-1, 1981.

[2] McCartney, B.L., Floating breakwater design. Journal of Waterway, Port, Coastal, and Ocean Engineering, 111(2), pp. 304-318, 1985. http://dx.doi.org/10.1061/(ASCE)0733-950X(1985)111:2(304)

[3] Murali, K. \& Mani, J.S., Performance of cage floating breakwater. Journal of Waterway, Port, Coastal, and Ocean Engineering, 123(4), pp. 172-179, 1997. http://dx.doi.org/10.1061/(ASCE)0733-950X(1997)123:4(172)

[4] Liang, N.K., Huang, J.S. \& Li, C.F., A study of spar buoy floating breakwater. Ocean Engineering, 31(1), pp. 43-60, 2004. http://dx.doi.org/10.1016/S0029-8018(03)00107-0

[5] Gesraha, M.R., Analysis of shaped floating breakwater in oblique waves: I. impervious rigid wave boards. Applied Ocean Research, 28(5), pp. 327-338, 2006. http://dx.doi.org/10.1016/j.apor.2007.01.002

[6] Dong, G.H, Zheng, Y.N., Li, Y.C., Teng, B., Guan, C.T. \& Lin, D.F., Experiments on wave transmission coefficients of floating breakwaters. Ocean Engineering, 35(8-9), pp. 931-938, 2008. 
http://dx.doi.org/10.1016/j.oceaneng.2008.01.010

[7] Wang, H.Y. \& Sun, Z.C., Experimental study of a porous floating breakwater. Ocean Engineering, 37(5-6), pp. 520-527, 2010.

http://dx.doi.org/10.1016/j.oceaneng.2009.12.005

[8] Uzaki, K., Ikehata, Y. \& Matsunaga, N., Performance of the wave energy dissipation of a floating breakwater with truss structures and the quantification of transmission coefficients. Journal of Coastal Research, 27(4), pp. 687-697, 2011. http://dx.doi.org/10.2112/JCOASTRES-D-09-00070.1

[9] Isaacson, M., Nonlinear-wave effects on fixed and floating bodies. Journal of Fluid Mechanics, 120, pp. 267-281, 1982. http://dx.doi.org/10.1017/S0022112082002766

[10] Fugazza, M. \& Natale, L., Energy losses and floating breakwater response. Journal of Waterway, Port, Coastal, and Ocean Engineering, 114, pp. 191-205, 1988. http://dx.doi.org/10.1061/(ASCE)0733-950X(1988)114:2(191)

[11] Koutandos, E., Prinos, P. \& Gironella, X., Floating breakwaters under regular and irregular wave forcing-reflection and transmission characteristics. Journal of Hydraulic Research, 43(2), pp. 174-188, 2005. http://dx.doi.org/10.1080/00221686.2005.9641234

[12] Jung, K.H., Chang, K.A. \& Huang, E.T., Two dimensional flow characteristics of wave interactions with a free-rolling rectangular structure. Ocean Engineering, 32, pp. 1-20, 2005. http://dx.doi.org/10.1016/j.oceaneng.2004.06.007

[13] Jung, K.H, Chang, K.A. \& Huang, E.T., Two dimensional flow characteristics of wave interactions with a fixed rectangular structure. Ocean Engineering, 31, pp. 975-998, 2004. http://dx.doi.org/10.1016/j.oceaneng.2003.12.002

[14] Drimer, N., Agnon, Y. \& Stiassnie, M., A simplified analytical model for a floating breakwater in water of finite depth. Applied Ocean Research, 14(1), pp. 33-41, 1992. http://dx.doi.org/10.1016/0141-1187(92)90005-5 